\title{
The strengthening mechanism of a magnesia core ceramic
}

\author{
W. J. O'Brien' ${ }^{1}$ C. L. Groh ${ }^{1}$, K. M. Boenke', \\ G.P. Mora' ${ }^{1}$ T.-Y. Tien ${ }^{2}$ \\ ${ }^{1}$ Department of Biologic and Materials Science, School of Dentistry and \\ ${ }^{2}$ Department of Materials Science Engineering, School of Engineering, The University of Michigan, Ann Arbor, MI , USA
}

\begin{abstract}
A high-expansion core material containing magnesia and forsterite may be used to make all-ceramic dental crowns with porcelain-fused-to-metal body porcelains. The purpose of this study was to investigate the strengthening mechanism for the magnesia core material. Six batches of the magnesia core material were made by reacting magnesia with a silica glass with holding times ranging from 17 to $120 \mathrm{~min}$. The flexural strength was measured using three-point loading according to the ISO specification for dental ceramics. The forsterite content was measured using quantitative $\mathrm{x}$-ray diffraction. A statistically significant correlation was found between the forsterite content and flexural strength. The proposed mechanism for strengthening is the precipitation of fine forsterite crystals in the glass matrix surrounding unreacted magnesia. Longer reaction times produced more dissolution of magnesia and subsequent precipitation of forsterite. This method results in a new strengthening mechanism for dental ceramics which have previously relied on the incorporation of alumina, leucite or ceramic whiskers.
\end{abstract}

\section{INTRODUCTION}

Porcelain jacket crowns have been used in dentistry since 1903. However, the low strengths of these materials precluded their widespread use. In 1965, the alumina-reinforced porcelain crown was introduced. A typical alumina-reinforced porcelain has a flexural strength of approximately $131 \mathrm{MPa}$, twice that of feldspathic porcelains. Other methods of reinforcing dental porcelains have since been developed.

Methods for determining the flexural strength of dental porcelains have been described by Jones et al. (1972) and Edwards et al. (1983). McLean and Hughes (1965), McLean (1967), McLean and Kedge (1987), and Seghi et al. (1990) have reported on the flexural strengths of various reinforced porcelains.

Magnesia is the basis of an experimental high expansion ceramic core material for the construction of all-ceramic dental crowns (O'Brien, 1985). Since the coefficient of thermal expansion of this core material has an average coefficient of expansion of $14.5 \times 10^{-6 / 0} \mathrm{C}\left(23^{\circ} \mathrm{C}-500^{\circ} \mathrm{C}\right)$, it can be used with body and incisal porcelains designed for bonding to metals (e.g., Ceramco II, Ceramco Inc., Burlington, NJ, USA; Vita VWK 68, Vident Inc., Baldwin Park, CA, USA; Crystar, Unitek Corp., Morovia, CA, USA; Will-Ceram, Williams Dental, Amherst, NJ, USA; Excelco
Porcelain, Excelco International, Deerfield Beach, FL, USA; etc.) to construct reinforced porcelain jacket crowns. This is not possible with aluminous core materials since they have coefficients of expansion around $8.0 \times 10^{-6} / \mathrm{C}$ and the porcelain-fused-to-metal porcelains have values around $13.5 \times 10^{-6} /{ }^{\circ} \mathrm{C}$. Flexural strength values for the magnesia core porcelain have been reported by O'Brien et al. (1988) and Hondrum and O'Brien (1988) to be 131 $\mathrm{MPa}$.

The purpose of this study was to investigate the strengthening mechanism for the magnesia core material. The hypothesis was that forsterite crystallization during the synthesis contributes to the strength as well as residual unreacted magnesia (O'Brien and O'Brien, 1986).

\section{MATERIALS AND METHODS}

Six batches of the magnesia core material were made by reacting $40 \%$ by weight of magnesia with $60 \%$ of a silica glass with the composition given in Table 1 . The temperature as a function of time was monitored using a platinum/platinum-rhodium $(10 \%)$ thermocouple and recorded (Model 660, Thermocouple Thermometer, Omega Engineering Inc., Stamford, CT, USA). The holding times at $1100-1150^{\circ} \mathrm{C}$ ranged between 17 to $120 \mathrm{~min}$ to form different quantities of forsterite $\left(\mathrm{Mg}_{2} \mathrm{SiO}_{4}\right)$ by the reaction:

$$
\begin{gathered}
\text { magnesia }(\mathrm{MgO})+\text { silicate glass containing titania } \\
\text { and zirconia }\left(\mathrm{SiO}_{2}+\mathrm{TiO}_{2}+\mathrm{ZrO}_{2}\right)--> \\
\text { forsterite }\left(\mathrm{Mg}_{2} \mathrm{SiO}_{4}\right)+\text { glass matrix }\left(\mathrm{SiO}_{2}\right) \\
+ \text { unreacted magnesia }(\mathrm{MgO})
\end{gathered}
$$

The frits were quenched in water and dried overnight. The materials were then pulverized with a mortar and pestle, ground (Model 155, Mortar Grinder, Fisher Scientific, Pittsburgh, PA, USA) and sieved (Model L3P, Sonic Sifter, Allen Bradley, Milwaukee, WI, USA) to obtain a fine powder. A series of sieves with openings of $2 \mathrm{~mm}, 500 \mu \mathrm{m}, 105 \mu \mathrm{m}, 74 \mu \mathrm{m}, 63 \mu \mathrm{m}, 53 \mu \mathrm{m}$, and $37 \mu \mathrm{m}$ were used to screen the powder.

The forsterite content of the magnesia core porcelains produced by different holding times was determined using quantitative $\mathrm{x}$-ray diffraction with silicon as the internal standard. In this method, a diffraction line from the phase being determined is compared with a line from a standard substance mixed with the sample in known proportions (Cullity, 1978). Four calibration standards were prepared with synthetic forsterite(Mason Colors, 
TABLE 1: COMPOSITION OF GLASS USED IN THE SYNTHESIS OF THE MAGNESIA CORE MATERIAL

\begin{tabular}{|cc|}
\hline Compound & Weight Percent \\
\hline $\mathrm{SiO}_{2}$ & 58.0 \\
$\mathrm{Al}_{2} \mathrm{O}_{3}$ & 1.5 \\
$\mathrm{TiO}_{2}$ & 5.0 \\
$\mathrm{ZrO}_{2}$ & 6.0 \\
$\mathrm{Na}_{2} \mathrm{O}$ & 10.0 \\
$\mathrm{~K}_{2} \mathrm{O}$ & 5.0 \\
$\mathrm{~B}_{2} \mathrm{O}_{3}$ & 9.5 \\
$\mathrm{~F}$ & 5.0 \\
\hline
\end{tabular}

East Liverpool, OH, USA) and the silica glass given in Table 1. The levels of forsterite in these standards were $30,50,70$ and 100 $\mathrm{wt} \%$, and the balance was the silica glass from Table 1. Eighteen parts of each standard were mixed with one part of silicon (Stock No. S-1053, Cerac Inc., Milwaukee, WI, USA) prior to x-ray analysis. Six x-ray diffraction patterns were recorded over the $2 \Theta$ range of $25-35^{\circ}$ for each of the standards using an x-ray diffractometer (ModelXRG-3000, Philips Electronic Instruments, Mount Vernon, NY, USA). In this $2 \Theta$ range, the forsterite peak at $32.4^{\circ}(\mathrm{d}=0.277 \mathrm{~nm})$ and a silicon peak at $28.7^{\circ}(\mathrm{d}=0.314 \mathrm{~nm})$ were suitable for quantitative analysis (Fig. 1). The calibration curve (Fig. 2) was the linear regression passing through the origin of the ratio of the peak intensities $\left(I_{\mathrm{f}} / I_{\mathrm{s}}\right)$ as a function of the weight fraction of forsterite $\left(\mathrm{W}_{\mathrm{f}}\right)$.

The forsterite contents of the six experimental batches were determined using the calibration curve generated above. Eighteen parts of the $<37 \mu \mathrm{m}$ particle size fraction of each batch were mixed with one part of silicon prior to $x$-ray analysis. Six $x$-ray diffraction patterns were recorded over the $2 \Theta$ range of $25-35^{\circ}$ for each of the batches. The ratio of the peak intensities $\left(\mathrm{l}_{\mathrm{f}}\right.$ at $32.4^{\circ} / \mathrm{l}_{\mathrm{s}}$ at $\left.28.7^{\circ}\right)$ was plotted on the calibration curve, and the weight fraction of forsterite $\left(\mathrm{W}_{\mathrm{f}}\right)$ was determined.

The bars for determination of flexural strength were fired at $1120^{\circ} \mathrm{C}$ with a 5 min hold (Cera-Mat III, Jelrus Technical Products Corp., New Hyde Park, NY, USA) for each of the six batches. The flexural strength was measured on a minimum of six $20 \times 5 \times 1.75 \mathrm{~mm}$ specimens per batch using three-point loading and following the ISO Specification 6872 (1984) for dental ceramics with a tension and compression tester (Model HTC, John Chatillon \& Sons, New York, NY, USA). A feldspathic porcelain and a reinforced porcelain (Brush Opaque, Excelco International; and Optec HSP, Jeneric/Pentron, Wallingford, CT, USA) served as controls. The results were analyzed by an ANOVA and Scheffé multiple comparisons test.

\section{RESULTS}

A summary of the synthesis, x-ray diffraction, and flexural strength results is provided in Table 2.

There is a high correlation $(\mathrm{R}=0.93, \mathrm{p}=0.022)$ between the weight fraction of forsterite formed and the holding times at $1100^{\circ} \mathrm{C}$. This is illustrated in Fig. 3.

Fig. 1 shows a diffraction pattern from the magnesia ceramic with the silicon standard. Analysis of the pattern showed the presence of $\mathrm{MgO}$, Si standard, and forsterite $\left(\mathrm{Mg}_{2} \mathrm{SiO}_{4}\right)$. The

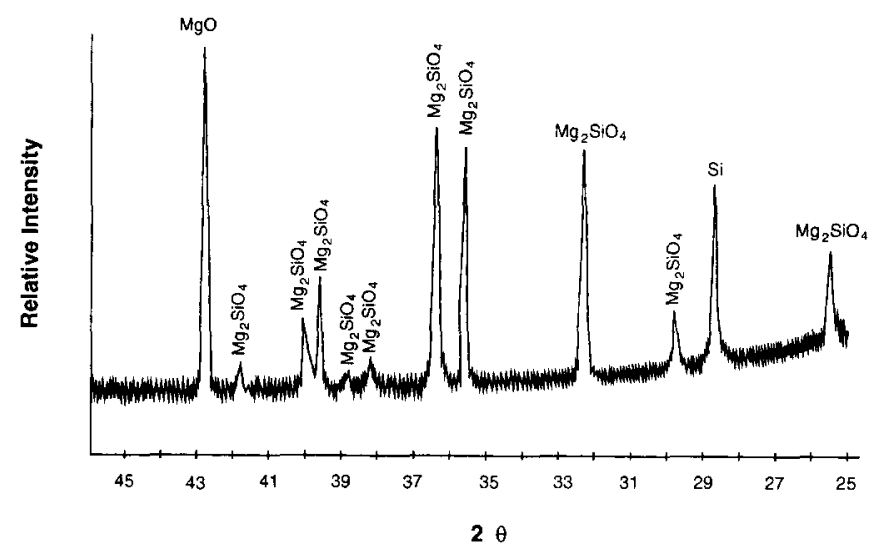

Fig. 1. An x-ray diffraction pattern of the magnesia ceramic with the silicon standard.

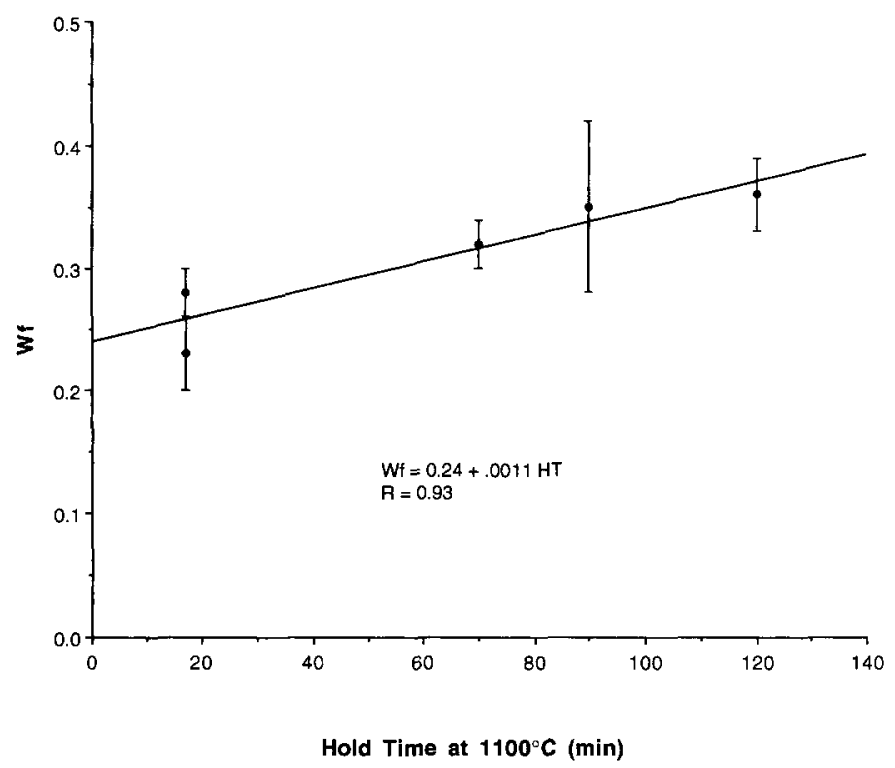

Fig. 2. The calibration curve generated by plotting the ratio of the peak intensities $\left(I_{f} / I_{s}\right)$ as a function of the weight fraction of forsterite $\left(W_{f}\right)$.

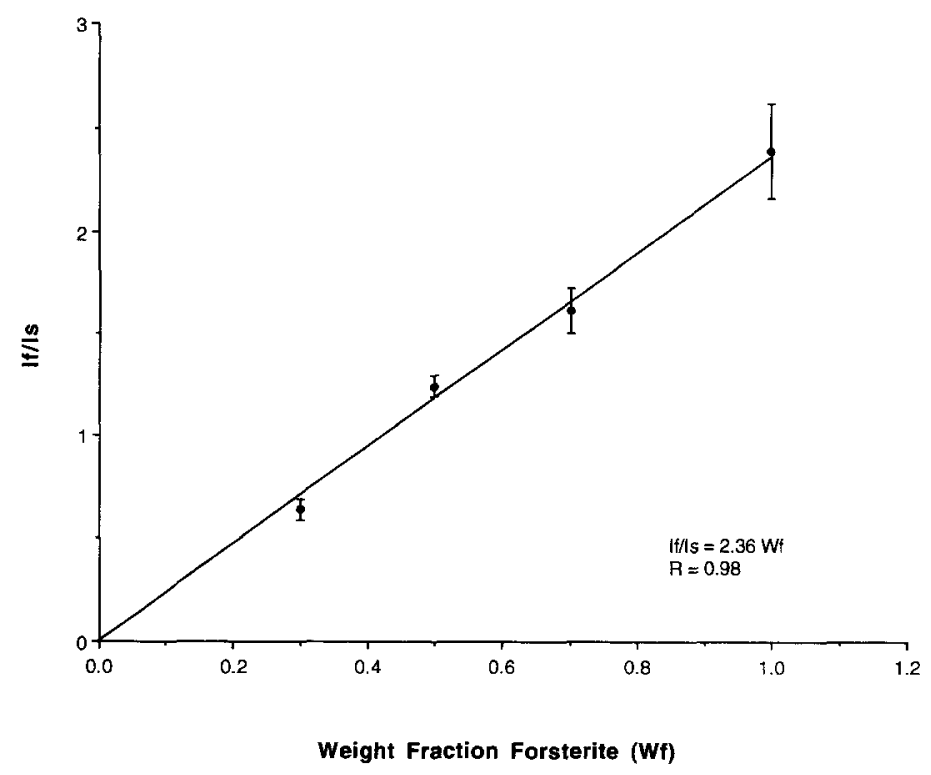

Fig. 3. The weight fraction of forsterite in the magnesia core material as a function of the holding time at $1100^{\circ} \mathrm{C}$. 


\begin{tabular}{|c|c|c|c|}
\hline \multicolumn{4}{|c|}{$\begin{array}{c}\text { TABLE 2: A SUMMARY OF THE RESULTS OF SIX BATCHES OF } \\
\text { MAGNESIA CORE MATERIAL }\end{array}$} \\
\hline Batch & $\begin{array}{l}\text { Hold Time } \\
\text { at } 1100^{\circ} \mathrm{C} \\
(\mathrm{min})\end{array}$ & $\begin{array}{l}\text { Weight Fraction } \\
\text { of Forsterite }\left(W_{1}\right) \\
\text { Mean (SD) }\end{array}$ & $\begin{array}{l}\text { Flexural Strength } \\
\text { (MPa) } \\
\text { Mean (SD) }\end{array}$ \\
\hline 51190 & 17 & $0.23(0.03)$ & $104(13)$ \\
\hline 51790 & 17 & $0.28(0.02)$ & $120(6)$ \\
\hline 70990 & 70 & $0.32(0.02)$ & $122(19)$ \\
\hline 91890 & 120 & $0.36(0.03)$ & $130(13)$ \\
\hline 121990 & & $0.42(0.03)$ & $140(12)$ \\
\hline 70291 & 90 & $0.35(0.07)$ & $145(9)$ \\
\hline
\end{tabular}

calibration curve for the forsterite, shown in Fig. 2, shows a high correlation $(R=0.98, p<0.0001)$ between the ratio of the peak intensities $\left(\mathrm{I}_{\mathrm{f}} / \mathrm{I}_{\mathrm{s}}\right)$ and the weight fraction of forsterite $\left(\mathrm{W}_{\mathrm{f}}\right)$.

The flexural strengths of the magnesia core material fritted for different times plotted against the mean weight fraction of forsterite is given in Fig. 4. The weight fraction of forsterite formed ranged from 0.23 to 0.42 , and the flexural strength values ranged from 104 to $145 \mathrm{MPa}$. An ANOVA and Scheffé test showed that there was a significant effect of batch on the flexural strength ( $p<0.0001$ ). Batch one was significantly weaker than batches four, five, and six, while batch six was significantly stronger than batches one and two (Table 2). Linear regression revealed a significant correlation $(R=0.88, p=0.022)$ between the mean forsterite contents and the mean flexural strengths. The average strength of the component glass (Table 1) was $51 \mathrm{MPa}$. Extrapolation of the linear regression line to zero forsterite content gave a strength value of $63 \mathrm{MPa}$. Results from previous studies (O'Brien et al., 1988; Hondrum and O'Brien, 1988) are within the range reported here. The feldspathic porcelain and the reinforced porcelain had flexural strengths of $101 \pm 8 \mathrm{MPa}$ and $152 \pm 8 \mathrm{MPa}$, respectively.

\section{DISCUSSION}

The internal standard method is valid only for integrated intensities. The peak height method of simply measuring maximum intensities is permissible when the shape of the diffraction lines is found to be essentially constant from sample to sample. As long as all patterns are made under identical experimental conditions, there is a constant proportionality between maximum and integrated intensities, and the measurement of maximum intensities gives satisfactory results (Cullity, 1978).

The correlation between flexural strength and forsterite content supported the hypothesis that the magnesia core material was strengthened by the dispersion of fine crystalline silicates in a glassy matrix (see Fig. 5) and indicated that forsterite makes a major contribution to the strength of the magnesia ceramic. Fig. 5 shows the microstructure of the fired magnesia ceramic which was prepared and finished to a $1 \mu \mathrm{m}$ diamond polish using standard metallographic procedures. A microprobe analysis showed the presence of unreacted magnesia and an amphorous matrix containing a fine precipitate of forsterite, smaller amounts of enstatite and minor amounts of magnesium zirconium silicate and magnesium titanium silicate compounds. The titanium dioxide and zironium oxides in the glass (Table 1) used to form the

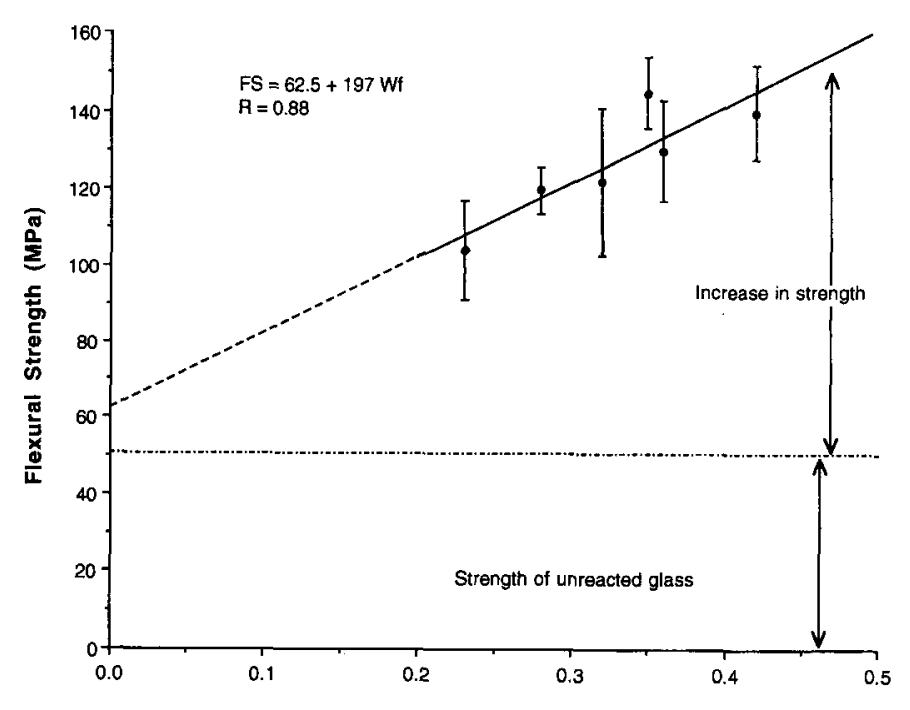

$\mathbf{W f}$

Fig. 4. The flexural strengths of the magnesia core material plotted against the mean weight fraction of forsterite.

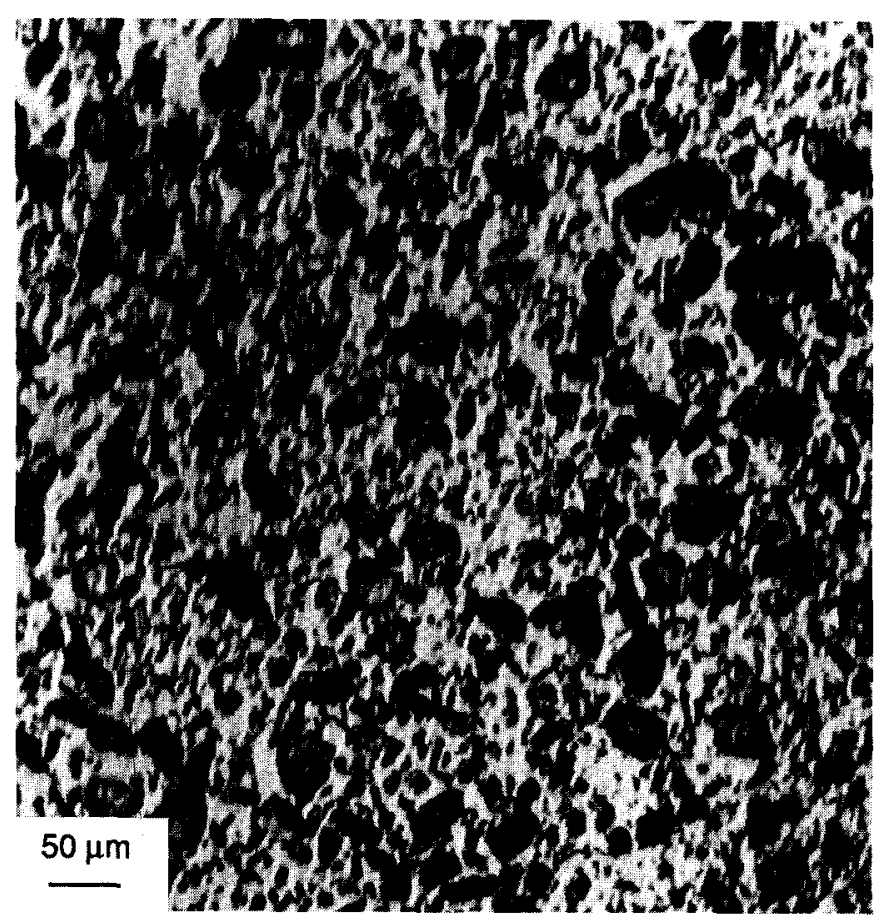

Fig. 5. The microstructure of the fired magnesia ceramic showing magnesia and reaction products dispersed in the matrix.

magnesia ceramic are known to be nucleating agents in glass crystallization (McMillan, 1979) and may contribute to the formation of forsterite and enstatite. The presence of minor amounts of magnesium zirconium silicates and magnesium titanium silicates may also contribute to the strengthening of the magnesia core material.

The proposed mechanism for strengthening is the precipitation of fine forsterite crystals in the glass matrix surrounding unreacted magnesia. Longer reaction times produced more dissolution of magnesia and subsequent precipitation of forsterite. This method results in a new strengthening mechanism for dental ceramics which have previously relied on the incorporation of leucite or alumina. 


\section{ACKNOWLEDGEMENTS}

The authors thank Warren Wagner for providing the microprobe analysis used in this study. This investigation was supported by Grant DE-09296 from the National Institute of Dental Research, National Institutes of Health, Bethesda, Maryland 20892, USA.

Received December 12, 1992/Accepted June 20, 1993

\author{
Address correspondence and reprint requests to: \\ W. J. O'Brien \\ Department of Biologic and Materials Sciences \\ School of Dentistry \\ The University of Michigan \\ $1011 \mathrm{~N}$. University \\ Ann Arbor, MI 48109-1078 USA
}

\section{REFERENCES}

Cullity BD (1978). Elements of X-ray Diffraction. 2nd ed., Reading, MA: Addison-Wesley, 407-420.

Edwards MR, Jacobsen PH, William GJ (1983). The three-point beam test for the evaluation of dental porcelain. $J$ Dent Res 62:1086-1088.
Hondrum SO, O'Brien WJ (1988). The strength of alumina and magnesia core crowns. Int $J$ Prosthodont 1:67-72.

ISO Specification 6872 (1984). International Organization for Standardization, Dental Ceramics Ref. No. ISO 6872-1984(E). Geneva, International Organization for Standardization.

Jones DW, Jones PA, Wilson HJ (1972). The relationship between transverse strength and testing methods for dental ceramics. J Dent 1:85-91.

McLean JW (1967). The alumina reinforced porcelain jacket crown. J Am Dent Assoc 75:621-628.

McLean JW, Hughes TH (1965). The reinforcement of dental porcelain with ceramic oxides. Br Dent $J$ 119:251-267.

McLean JW, Kedge MI (1987). High strength ceramics. Quint Int 18:97-106.

McMillan PW(1979). Glass Ceramics. 2nd ed., London:Academic Press, 74-76, 84.

O'Brien WJ (1985). Magnesia ceramic jacket crowns. Dent Clin North Am 29:719-724.

O'Brien WJ, O'Brien MT (1986). High expansion dental crown core ceramic composition. U.S. Patent 4,576,922.

O'Brien WJ, McPhee ER, Seluk LW (1988). Strength of a highexpansion core porcelain. In: Preston JD, ed. Perspectives in Dental Ceramics. Proceedings of the Fourth International Symposium on Ceramics. Chicago: Quintessence Publishing Co., Inc., 167-174.

Seghi RR, Daher T, Caputo A (1990). Relative flexural strength of dental restorative ceramics. Dent Mater 6:181-184. 